\title{
Событийность человека в городском пространстве: между модернизацией и экзистенциальной памятью
}

\author{
Ромащенко А.А. \\ Саратовский государственный технический университет имени Гагарина Ю.А., \\ Россия, 410054, Саратов, Политехническая, д. 77. \\ E-mail: romaschenko.al@gmail.com
}

\begin{abstract}
Аннотация. Опираясь на герменевтическую и феноменологическую методологию М. Хайдеггера, автор статьи проводит сравнительный анализ двух типов понимания человеческого сообщества в рамках урбанизированного пространства: с одной стороны, человек, включенный в городское сообщество, находится в условии необходимости принятия перманентных процессов модернизации пространства города; с другой - данные процессы вместе с обновлением условий существования человека, с привнесением в них комфорта и чистоты способствуют утрате объектов индивидуальной памяти. Феноменологическая методология анализа данной проблемы дает возможность увидеть за модернизированным пространством города утрату человеческой идентичности, целостности, и формирование человека как элемента потребительских отношений (и как субъекта, и как объекта потребления). Экзистенциально-феноменологическое понимание человека, включенного в контекст урбанистического пространства, расширяет рамки субъектобъектного подхода и позволяет распознать за субъективностью новые экзистенциальные формы (Dasein как присутствие), которые связаны как с проблемой временности существования человека, так и пространственной событийностью. Событийность человеческого присутствия в городе понимается автором статьи многогранно: событийность с Другим (совместное существование человека в сообществе), событийность как мыслительный акт субъективации, основанный на принятии факта временности, а также событийность в качестве пространственной наполненности города объектами индивидуальной экзистенциальной памяти. В последнем случае к таким объектам автор вслед за Г. Зиммелем относит руины.
\end{abstract}

Ключевые слова: ностальгия, город, инновации, пространство, время, урбанизация, субъективация, Dasein, руина.

Для цитирования: Ромащенко А.А. 2020. Событийность человека в городском пространстве: между модернизацией и экзистенциальной памятью. NOMOTHETIKA: Философия. Социология. Право. 45 (3): 468-477. DOI 10.18413/2712-746X-2020-44-3-468-477

\section{Human eventfulness in the city space: between modernization and existential memory}

\author{
Alexander A. Romashchenko \\ Yuri Gagarin State Technical University of Saratov, \\ 77 Politekhnicheskaya St, Saratov, 410054, Russia \\ E-mail: romaschenko.al@gmail.com
}

\begin{abstract}
The article is devoted to the problem of human identification in urban space. The author uses M. Heidegger's phenomenological methodology. This methodology allows to reveal the duality of the situation in which a person is found as a member of the urban community. The modernization of the conditions of human existence in city leads to delamination of the person. The security requirements of urban communities as a condition of modernization transforms a person into a subject of action and an object of consumption. According to the author, overcoming such a situation is possible in the event of an
\end{abstract}


expansion of the scope of understanding of the person. In the phenomenological sense, man is not the subject of his act or thought, but «Dasein», «existence», «presence». This understanding of the person takes into account many factors: the internal existential openness and mood of the person, the external intention focused on the spatial presence of the person. Both sides of this understanding are expressed according to the author in the eventfulness of man. Eventfulness of human presence in the city is understood by the author of the article in many ways: eventfulness with Another (co-existence of a person in a community), eventfulness as a mental act of subjectivation based on the acceptance of the fact of selftemporality, as well as eventfulness as a spatial occupancy of the city objects of individual existential memory. In the latter case, the author after G. Simmel refers to such objects as ruins.

Key words: Nostalgia, city, innovation, space, time, urbanization, subjectivity, Dasein, ruins.

For citation: Romashchenko A.A. 2020. Human eventfulness in the city space: between modernization and existential memory. NOMOTHETIKA: Philosophy. Sociology. Law series. 45 (3): 468-477 (in Russian). DOI 10.18413/2712-746X-2020-44-3-468-477

\section{Введение}

Проблема, вынесенная в заглавие этой работы, коррелирует со спецификой современного философского дискурса, которая заключается в своеобразном (пере)открытии человека в XX веке, понимаемом как инстанция, нуждающаяся в прояснении дополнительными средствами: средствами языка, средствами произведения искусства или социальнополитическими институтами субъективации. Одной из форм рецепции человека в рамках современной философии становится его экзистенциальное понимание, стремящееся к преодолению рациональности субъект-объектного подхода и формирующее контрметафизические практики, сообразуемые в частности с различными аспектами социального взаимодействия. Результатом такой философской рецепции человека становится открытие его особой формы понимания через немецкое Dasein (русское «присутствие» [Бибихин, 1993; Васильев, 2018]), связанное как с мыслительным усилием в качестве практики самобытия (у Мамардашвили это прустовское «усилие во времени» [Мамардашвили, 2014]), с одной стороны, так и с местом (миром), в котором осуществляется присутствующее мышление, - с другой. Для такой экзистенциальной рецепции человека и мира в рамках философского дискурса сегодня необходимо феноменологическое и герменевтическое уточнение, в котором человек как присутствие в полной мере раскрывается через своеобразные формы события, понятого как качественное изменение знания о себе (осознание временности своего существования [Хайдеггер, 2003]), практика и эстетика заботы о себе [Фуко, 2006; Федичева, 2010; Лишаев, 2013]), так и сосуществования с другими (со-бытия) [Арендт, 2000]. Практика события человека в рамках современной философии выстраивает понимание человека, основанное на его участии (негативном ли, позитивном ли) в некоем сообществе, формы бытия которого собственно константны для всех возможных дискуссий о человеке. Овеществленной формой бытия человека в сообществе является городское пространство, в котором разворачивается своеобразный конфликт, выраженный в столкновении таких полярных констант, как «старое - новое», «коллективное - индивидуальное», «метафизическое - экзистенциальное».

Герменевтическая и феноменологическая методология, применяемая в данном исследовании, способна раскрыть многообразие практик субъективации человека в рамках постоянно изменяемого пространства городской среды. В то время как западная философия уже давно включила в круг своих интересов проблемы урбанизации как формы эстетической субъективации [Линч, 1982 Бодрийяр, 2001; Зиммель, 2002; Беньямин, 2013;], в российском научном пространстве попытки метафизического и экзистенциальнофеноменологического осмысления города как практики субъективации начинаются лишь с 90-х годов XX века и ознаменованы многочисленными исследованиями [Метафизика 
Петербурга, 1993], в которых разворачивается последовательное применение указанной методологии применительно к конкретной урбанистической ситуации [Фокина, 1998; Рещикова, Фокина, 2007; Лишаев, 2014, 2015], сопоставление тематик городского пространства и языковых практик [Вахштейн, 2014], слияние теории и практики урбанизма с феноменологическим прочтением связки человек-город [Веселова, 2015].

\section{Безопасное городское пространство как объект потребления}

Современное общество немыслимо без совместно организуемого жизненного пространства [Лефевр, 2015]. Если в традиционном обществе данное пространство обживалось спонтанно, то общество XX-XXI веков благодаря развитию техники, науки, социально-экономических факторов способно организовывать и реорганизовывать место своего обитания самостоятельно и независимо от природы. В случае с эко-поселениями дело обстоит так же, поскольку любая форма поселения - это движение вдоль линии «природное - искусственное» [Веселова, 2015]. Практики сакрализации пространства, политизация места в древнем сообществе (полис) приводит к возникновению особого пространства жизни человека как урбанизированного пространства, подверженного постоянным преобразованиям. Преобразования ландшафта в городскую среду определяется, прежде всего, соображениями безопасности, которые стоят на первом месте в большинстве инновационных проектов. Целью таких проектов является противопоставление безопасного городского сообщества внешней и внутренней угрозе. К внешней угрозе можно отнести, прежде всего, природные стихии [Веселова, 2015]; к внутренней - аффективность человека. Стихийность природного начала - это непосредственная внешняя опасность, заставляющая прятаться в пещеру, квартиру, дом, создавать город как безопасную среду обитания для человеческого сообщества, покинувшего природу и противопоставившего себя ей. Опосредованная внешняя опасность природной стихии связана с внутренней способностью человека к рефлексии всего естественного, принятием или отторжением естественных фактур, где акт восприятия эстетически посредует отношения человека и природы. Во многом это связано с эстетизацией пространства-поверхности, в которой всякое естественное и самостоятельное рассматривается в качестве уродливого, подлежащего либо облагораживанию (модернизации), либо укрощению. Эстетика поверхности становится условием и предпосылкой формирования замкнутого (в пространственном понимании) коллективного сообщества человека, противопоставившего себя природе.

Аффективная природа человека роднит его со стихиями, допускает неповиновение и движение наперекор прямой линии. Если в первом случае опасность продиктована извне, то во втором - она исходит изнутри. Однако так же, как в первом случае перед нами - эстетизация пространства-поверхности, во втором - эстетизация акта, длящегося во времени. Жизненное пространство городского сообщества противопоставляет себя этой угрозе, устанавливая правила поведения, находящиеся в плоскости визуального контакта: правила и направление перемещения, движения, время пребывания, время работы. Визуальность и наглядность этих правил продиктована невидимостью властного органа, организующего это жизненное пространство, поскольку в обратном случае при визуализации власти образ властного органа оттягивал бы на себя внимание путем эстетической интерпретации этого образа, а правило как непреложное указание не смогло бы выполнять свою функцию, так как целиком и полностью зависело бы от эстетической интерпретации. Эстетизация контроля подспудно предполагает многовариантную трактовку правила, что идет в разрез с природой контроля. Тем самым власть, организующая современное пространство города, имеет рациональную, сверхчувственную (внеэстетическую) природу, направленную посредством видимых правил-маркеров против эстетизации пространстваповерхности (в том числе и против вандализма) и эстетизации акта, измеряемого временными величинами (акция, событие, шествие). 
Помимо непосредственных указателей, коими пестрит городская среда обитания человека, присутствие власти отмечается наличием видеокамер, чья исполняемая роль двояка [Жижек, 2012]. С одной стороны, видеонаблюдение сдерживает «живые» порывы человека. Однако с другой, - реализация способов видеофиксации определяется формой самих властных отношений, приобрётших начиная с XVIII века вид «дисциплинарного контроля», у которого имеется два истока. Во-первых, мобильность индивидов, включенных в данное пространство. Контроль перемещения индивидов выражен в появлении социальных институтов и нормировании времени, призванных фиксировать присутствие человека в определенном месте и времени [Бокарева, 2019]. Во-вторых, дисциплинарность городского пространства связана косвенно с «высокомерием большого города» [Зиммель, 2002], которое формируется в качестве реакции на увеличивающиеся темпы усложнения среды, в которой вынуждены обитать городские сообщества; а непосредственно - с эффектом «Self-made», являющимся наследником высокомерного индивида, который вырабатывает «бесчувственное равнодушие» к человечности (интимности) и традиционной сплоченности сообществ как следствие частых контактов с массовой формой существования [Веселова, 2015]. Человек в такой перспективе включен в паноптическую рецепцию властных отношений как объект надзора в клинике, тюрьме, школе. Дисциплинарность социальных институтов воспринимаются как благо, направленное на обеспечение безопасности; они придают пространству характер публичности, где нивелируется угроза как внешнего характера, так и внутреннего. А это, в свою очередь, определяет отношения между человеком и публичным пространством как отношения потребления. Безопасное пребывание человека в пространстве города - это объект потребления, цена которого индивидуальность. Помимо индивидуальности как платы за потребляемую безопасность, человек лишается еще и целостности, поскольку любое санкционированное и легальное видеонаблюдение, обеспечивающее безопасность, сопровождается информацией о наличии видеокамеры, что, по сути, приводит к манипуляции с самостоятельностью и целостностью человека: в ситуации дисциплинарного контроля человек расслаивается на скрытого субъекта своего поступка и собственно объективного исполнителя роли публичного субъекта. Поэтому современное инновационное преобразование и модернизация жизненного пространства городского сообщества, являясь объектом потребления (а равно и экономической целесообразности), влечет за собой формирование безопасного пространства индивидов, лишенных своей уникальной, интимной целостности.

\section{Экзистенциальная перфективность ветхого предмета и целостность человека}

Своеобразной формой преодоления обезличенности и раздробленности человека в городской среде может стать визуализация многочисленных форм экзистенциальной памяти, к которым относятся элементы самой городской среды, связанные с индивидуальными, личностными переживаниями. Жизненное пространство городских сообществ, связанное с экзистенциальными переживаниями, с ностальгией как тоской не столько по Родине, сколько по прошлому вообще, - это неотъемлемое качество целостной личности, которая организует свою целостность через обращение к прошлому, то есть посредством времени. При этом ностальгия как чувственно-эмоциональная подоснова практики и культуры возвращения к себе - это одновременно и практика, направленная на формирование целостности своего бытия-в-мире, где экзистенциальный мыслительный акт с необходимостью понимается как событие, разворачивающееся не только с течением времени (в том числе и с целью принятия своей временности), но и в контексте пространства, организующего протяженные формы «вокруг» бытия-в-мире. Несмотря на то, что связка пространства-времени - это маркер метафизического понимания бытия человека, в современной философской ситуации эти маркеры сохраняются в качестве экзистенциальной формы пе- 
реживаемости пространственно-протяженных и длительно-временных констант своего индивидуального присутствия (Dasein).

Так же как социальная память, выраженная отчасти в форме организации музейного пространства как элемента модернизированного жизненного пространства городских сообществ, связана с противопоставлением себя стихии, точно так же экзистенциальная личностная память противостоит стихии времени, но при этом время как сила, направленная на физическое уничтожение объекта памяти (порча, коррозия, износ, ветхость), в рамках экзистенциально-личностного понимания города играет своеобразную роль.

С одной стороны, время является объектом, против которого направлена как модернизация жизненного пространства, так и все попытки сохранить объект индивидуальной памяти. Однако, с другой стороны, именно время придает старинному объекту то неповторимое своеобразие, которое привлекает внимание обладателя данного предмета (особенно, если с этим предметом связано экзистенциальное переживание человека). При этом какая бы то ни было модернизация исторического объекта (приведение ветхости к стандартам современности) превращает само время в объект потребления, что хорошо видно на примере институциализации музейного пространства, в котором осуществляется акт потребления времени вместе с модернизированным (включенным в музейное пространство) объектом экзистенциальной памяти.

Так как модернизация чаще всего связана с полным обновлением объекта потребления (зачастую с его заменой) в контексте не только его безопасности, но во многом его функциональности, экзистенциальная память сама по себе (а также и объект памяти) оказывается в ситуации исключения, поскольку связывает человека не с потребляемым им продуктом (услугой), а с историей и мифологией в той проекции, которую нельзя сделать частью акта потребления. А так как исторический объект чаще всего не укладывается в нормы модернизации, чистоты, безопасности или материальной целостности (исторически ветхий объект - это, прежде всего, объект распада), то в плане самой модернизации городского пространства как объекта потребления он выведен за скобки.

Исключением служат исторические объекты, включенные в контекст модернизированного пространства города в качестве музейного экспоната. Однако в данном случае история связана не с индивидуальной историей конкретного человека, а с историей как формой социальной памяти, в которой конкретный человек может предстать в виде героической личности, участника великих свершений или свидетеля знаковых перемен. Но даже и в этом случае уникальная личность, ставшая поводом организации музейного пространства (например, дом-музей какого-либо писателя), все же не может быть целостной, поскольку налицо разобщенность повседневного экзистенциального переживания этой личности (скрытого от глаз наблюдателя), с одной стороны, и экспонированного предмета исторической памяти, - с другой. Экзистенциальная же форма личностной памяти в такой перспективе исключена из процесса модернизации именно в силу той целостности, которую дарит старинный предмет своему обладателю и которая присуща такой форме памяти. Так, Жан Бодрийяр в работе «Система вещей» объединил данное понимание старинной вещи и связанную с ней целостность человеческой личности с завершенностью (перфективностью) самого предмета. По его мнению, функциональность предмета, услуги, явления представляет собой ту силу, которая лежит в основе потребительского отношения человека к предмету: «Императив, которому отвечают старинные вещи, - это императив завершенного, законченного в себе существа. Время, в котором живет мифологический предмет, - перфект; это то, что имеет место в настоящем в качестве сбывшегося прежде и что в силу этого глубоко укоренено в себе самом, то есть подлинно... Этого, разумеется, недостает функциональным вещам, которые существуют лишь ныне, в актуальном индикативе или практическом императиве, исчерпываясь своим применением и не обладая предшествующим бытием; более или менее заполняя собой пространство, они не обеспечивают наполненность времени. Функциональная вещь обладает эффективностью, 
мифологическая вещь - завершенностью» [Бодрийяр, 2001, с. 85]. При всей своей (контр)функциональности исторический и мифологический предмет, отсылающей человека в прошлое, организует пространство человеческого существования не с позиций потребления, свойственного модернизированному пространству, а в качестве своеобразной силы, консервирующей время в самом себе и тем самым способствующей самостоятельности человеческого существования, включенного в отношения с данным историческим предметом, вопреки несамостоятельности расколотого на части человека потребления: «Мифологический предмет, символизируя собой схему включения ценностного смысла в замкнутый круг завершенного времени, представляет собой дискурс, обращенный уже не к другим, а к себе. В своем довременном состоянии эти баснословные вещи-острова отсылают человека к детству или даже к еще более дальней пренатальной стадии, где чистая субъективность вольно-метафорически выражала себя в окружающей "среде", а сама эта "среда" была лишь безупречным самонаправленным дискурсом человеческого существа» [Бодрийяр, 2001, с. 90].

Таким образом, Бодрийяр моделирует экзистенциальную форму личностной памяти человека в его связке с предметностью в качестве мифологизации «баснословных вещей-островов», отсылающих их обладателя к двум формам бытия-в-мире: детству и некой «пренатальной стадии». В первом случае бытие-в-мире организует такое отношение к мифологическому предмету как свидетелю становящейся экзистенции (своеобразное предметное присутствие рядом). Такие присутствующие рядом в потоке становящейся экзистенции объекты впоследствии и сообщают своему обладателю целостность. Естественно такой предмет, включенный в круг становления частного присутствия, не может быть по определению объектом потребления в полном объеме ни в каком виде: даже в качестве музейной ценности данный мифологический предмет всегда будет объектом отвлеченного характера, то есть объектом потребления, разглядывания, выставления, но никак не частью индивидуального становления.

Однако в отношении «пренатальной стадии» чувственно-эмоциональная привязанность человека к предмету историко-мифологического характера распространяется так же на те фрагменты пространственной протяженности (во времени), которые непосредственно не связаны со становящейся экзистенцией. В.В. Набоков характеризует такую связь как болезненное чувство безграничного прошлого: «Я знавал, впрочем, чувствительного юношу, страдавшего хронофобией и в отношении к безграничному прошлому. С томлением, прямо паническим, просматривая домашнего производства фильм, снятый за месяц до его рождения, он видел совершенно знакомый мир, ту же обстановку, тех же людей, но сознавал, что его-то в этом мире нет вовсе, что никто его отсутствия не замечает и по нем не горюет» [Набоков, 1990, с. 133]. Чувство временности в данном случае направлено не в будущее (становящееся присутствие всегда становится из прошлого в будущее), а в прошлое, где состоявшееся событие (мифологический предмет в прошедшем времени и совершенном виде) собирает в единое целое экзистенциальное присутствие в настоящем (для будущего). Для Бодрийяра такая целостность маркируется единством присутствующего сегодня человека с мифологическими истоками подлинности: «... в мифологии старинных вещей следует различать два аспекта - ностальгическое влечение к первоначалу и обсессию подлинности. И то и другое, по-видимому, вытекает из мифической отсылки к рождению, каковую представляет собой старинная вещь в своей временной замкнутости; действительно, всякая рожденность предполагает наличие отца и матери. Инволюция к истокам - это, разумеется, регрессия в материнскую утробу; чем более старинны вещи, тем более они приближают нас к некоей оставшейся в прошлом эпохе, к "божеству", к природе, к первобытным знаниям и т.д.» [Бодрийяр, 2001, с. 86]. Мифологичность ветхого для Бодрийяра выражена в мифологии первоистока: «Знаменуемое ею состоявшееся событие - это событие рождения. Я - не тот, кто живет сегодня (в этом мой страх), я тот, кто уже был раньше, согласно логике обратного 
рождения, знаменуемого мне таким предметом, который из настоящего устремлен в глубь времени; это и есть регрессия. Таким образом, старинная вещь выступает как миф о первоначале» [Бодрийяр, 2001, с. 85].

\section{Пространственно-временная событийность руин}

Экзистенциальная форма переживания временности своего присутствия в мире может быть связана так же с такими объектами, которые выходят за временные границы самого присутствия. К таким объектам и относятся предметы старины, которые официально (то есть с потребительской точки зрения) окружены ареалом мифа (политического, эстетического, идеологического характера), а в отношении конкретного индивидуального существования способны дать нам впечатление целостности (однако при выполнении ряда условий, среди которых отказ от потребительского отношения к предмету, от потребительского отношения к месту и ко времени).

Среди таких мифологизированных объектов старины в рамках урбанизированного жизненного пространства можно выделить такие, к которым, благодаря Г. Зиммелю, применяется эпитет «руины» [Зиммель, 1996]. Руины выражают в себе всю полноту понимания таких объектов, которые можно подвести под следующие понятия: историчность экзистенциальной памяти, ностальгия, экзистенциальная форма памяти. Для Зиммеля руины - это наследники зодчества, в котором приобретает наглядные очертания единство «стремящейся вверх души» и «стремящейся вниз тяжести» природы: «Это неповторимое равновесие между механической, тяжелой, пассивно противодействующей давлению материей и формирующей, направляющей ввысь духовностью нарушается в то мгновение, когда строение разрушается. Ибо это означает, что силы природы начинают господствовать над созданием рук человеческих: равенство между природой и духом, которое воплотилось в строении, сдвигается в пользу природы. Этот сдвиг переходит в космическую трагедию, которая вызывает печаль в нашем восприятии каждой руины: разрушение предстает перед нами как месть природы за насилие, которое дух совершил над ней, формируя ее по своему образу» [Зиммель, 1996, с. 226]. Руинизированное зодчество, тем самым, - это, по существу, возвращающаяся в недра природы тяжесть ее материального субстрата, бессилие духа, поддавшегося неумолимости времени.

Зиммель указывает на факт своеобразной привлекательности руины. По крайней мере, два фактора можно выявить внутри механизма этой привлекательности. Во-первых, собственно время. Именно временность, сокрытая в руине, и привлекает человека к мифологически насыщенному пространству заброшенного места: «Руина создает в настоящем форму прошедшей жизни, и не по ее содержаниям или следам, а по ее прошлому как таковому. В этом и состоит очарование древностей... Здесь действует душевная целостность, которая, как и ее объект, охватывает прошлое и настоящее слитыми в единую форму, охватывает всю сферу телесного и духовного видения в эстетическом наслаждении, коренящемся в единстве более глубоком, чем единство эстетического наслаждения» [Зиммель, 1996, с. 232]. Время руины, заброшенного места, места экзистенциальной памяти, как было указано выше, придает объекту завершенный характер, перфективное качество. Перфективность руины (в бодрийяровском смысле) сказывается на человеке, причастном этому объекту, таким образом, что несовершенство ветхого (руинизированная урбанистическая ситуация) парадоксальным образом сказывает совершенство человеку, который включен в эстетическое событие руин.

Событийность руинизированного пространства возможна лишь в том случае, когда человек включен в это событие, и не возможна, когда человек относится к пространственно-временной форме своего собственного бытия-в-мире с потребительскифункциональным предпониманием и настроением. Разница включенности человека в событие ветхого и исключенности его из игры «прошлого-будущего» формируется в совре- 
менной философии в качестве практики себя. С.А. Лишаев противопоставляет два типа эстетики: «эстетика существования», которая открывает для себя руины как внешнюю форму перфективности человека и «эйдетическая эстетика», подчиненная сущностному целеполаганию [Лишаев, 2015,]. Эстетика существования организует целостность собственного бытия-в-мире на основе созерцания и фундаментальной заинтересованности в пространственно-временном событии становящегося присутствия, в котором нет различения между наблюдателем и наблюдаемым предметом (что характерно по существу для эйдетической эстетики), в котором целостность присутствия обнаруживается через ветхость и преходящий характер наблюдаемых (включенных в присутствие) предметов. При этом модернизация урбанистического жизненного пространства, придание эффективности, функциональности и утилитарности предметам, включенным в событие присутствия - это тоже своеобразная эстетика существования, которая заключается в таком расположении бытия-в-мире, при котором само присутствие в соответствии с таким образом понятой эстетикой существования так же включается в игру утилитаризации и функциональности. Функциональность присутствия предполагает фрагментацию целостного экзистенциального бытия-в-мире в соответствии с правилами потребления.

\section{Заключение}

Таким образом, современная философия, осуществляя акт переоткрытия человека, делает это, привлекая в контекст человекоцентричности своего дискурса своеобразную чувствительность, которая выражается как в языке современной философии, стремящемся во многом к поэтизации, так и в предметном поле, формируемом зачастую в качестве следствия данной чувствительности. Начиная с ранних работ М. Хайдеггера, такие понятия, как «настроение», «забота», «озабоченность», «план» [Хайдеггер, 2003] становятся формой отражения (переживания) бытия человека, который, во-первых, не может в такой перспективе пониматься как субъект, а, во-вторых, не мыслим вне связей, в которые он погружен в силу своего событийного характера: нахождение себя в отношениях с Другими. Отвергая субъективность как меру самостоятельности, современная философия видит самобытие человека в таких явлениях, которые в допредикативной форме отражают интенциональность собственно бытия: присутствие, Dasein, вот-бытие. Распределение таких интенциональных качеств человека на событийность его существования позволяет увидеть в Dasein (присутствии) не только временность, но и экзистенциальные формы пространственного соучастия, которые выражаются в частности в существовании человека в контексте урбанизированного пространства.

\section{Список источников}

1. Беньямин В. 2013. Краткая история фотографии. М., Ад Маргинем Пресс: 144 с.

2. Жижек С. 2012. Год невозможного. Искусство мечтать опасно. М., Издательство «Европа»: 272 с.

3. Набоков В.В. 1990. Собрание сочинений. Т. 4. Другие берега. М., Издательство «Правда»: $412 \mathrm{c.}$

4. Simmel G. 1903. Die Grossstaedte und das Geistesleben. Die Grossstadt. Jahrbuch der GeheStiftung zu Dresden, 9. 185-206.

\section{Список литературы}

1. Арендт X. 2000. Vita activa, или О деятельной жизни. Пер. с нем. и англ. В.В. Бибихина. СПб., Алетейя, 437 с.

2. Бибихин В.В. 1993. Дело Хайдеггера. В кн.: Хайдеггер М. Время и бытие. Статьи и выступления. М., Республика: 3-14.

3. Бодрийяр Ж. 2001. Система вещей. М., Рудомино: 220 с. 
4. Бокарева О.Б. 2019. Концепция власти и понятие «Власть - знание» в философии Мишеля Фуко. Международный журнал гуманитарных и естественных наук, 3(1): 172-175.

5. Васильев В.Ф. 2018. Dasein как присутствие (Герменевтика). Вестник социальнополитических наук, 17: 68-70.

6. Веселова С.Б. 2015. Город. Между архитектурным проектом и информационной сетью. URL: https://ridero.ru/books/gorod_mezhdu_arhitekturnym_proektom_iinformacionnoj_setyu/ (Дата обращения: 10.12.2019).

7. Зиммель Г. 1996. Избранное. Т. 2. Созерцание жизни. Руина. М., Юристъ: 226-233.

8. Лефевр А. 2015. Производство пространства. M., Strelka Press: 432 с.

9. Линч К. 1982. Образ города. М., Стройиздат: 328 с.

10.Лишаев С.А. 2013. Игра руин (материалы к эстетической аналитике руин). В кн.: Mixtura verborum' 2013: время, история, память: философский ежегодник. Под общ. ред. С.А. Лишаева. Самара, Самарская гуманитарная академия: 84-100.

11. Лишаев С.А. 2015. Эстетика руин. В кн.: Ежегодник по феноменологической философии. М., Издательский центр РГГУ: 87-114.

12. Мамардашвили М.К. 2014. Психологическая топология пути. Т. 2. М., Фонд Мераба Мамардашвили: $1232 \mathrm{c.}$

13. Метафизика Петербурга (Петербургские чтения по теории, истории и философии культуры). 1993. Вып.1. СПб., Эйдос: 315 с.

14. Рещикова И.П., Фокина Т.П. 2007. Саратов в метафизическом наряде. Обсерватория культуры, 3: 130-137.

15. Федичева К.В. 2010. Забота о себе: философский, онтологический и этический аспекты. Вестник Ленинградского государственного университета им. А.С. Пушкина, 2(3): $136-144$.

16. Фокина Т.П. 1998. Метафизика Саратова. Волга, 1: 167 с.

17. Фуко М. 2006. Эстетика существования. В кн.: Интеллектуалы и власть: Избранные политические статьи, выступления и интервью. Ч. 3. М., Праксис: 320 с.

18. Хайдеггер М. 2003. Бытие и время. Харьков, Фолио, 503 с.

\section{References}

1. Arendt H. 2000. Vita activa, ili O deyatel'noy zhizni [Vita activa, or About active life]. Spb., Publ. Aleteia: $437 \mathrm{p}$.

2. Bibikhin V. V. 1993. Delo Khaydeggera [Heidegger case]. V kn: Khaydegger M. Vremya i bytiye. Stat'i i vystupleniya [Time and Being. Articles and Speeches]. M., Publ. Respublika: 3-14.

3. Baudrillard J. 2001. Sistema veshchey [System of things]. M., Publ. Rudomino: 220 p.

4. Bokareva O. B. 2019. Kontseptsiya vlasti i ponyatiye «Vlast' - znaniye» v filosofii Mishelya Fuko [The concept of power and the concept of "Power is knowledge" in the philosophy of Michel Foucault]. International Journal of Humanities and Natural Sciences, 3(1): 172-175.

5. Vasil'yev V.F. 2018. Dasein kak prisutstviye (Germenevtika) [Dasein as Presence (Hermeneutics)]. Herald of Social and Legal Sciences, 17: 68-70.

6. Veselova S. B. 2015. Gorod. Mezhdu arkhitekturnym proyektom i informatsionnoy set'yu [City. Between architectural design and information network]. Available at: URL: https://ridero.ru/books/gorod_mezhdu_arhitekturnym_proektom_iinformacionnoj_setyu/ (Accessed 10.12.2019).

7. Zimmel' G. 1996. Izbrannoye. T. 2. Sozertsaniye zhizni. Ruina [Favorites. Vol. 2. Contemplation of life. Ruin]. M., Publ. Yurist: 226-233

8. Lefevr A. 2015. Proizvodstvo prostranstva [The production of space]. M., Strelka Press: 432 p.

9. Linch K. 1982. Obraz goroda [Image of the city]. M., Publ. Stroyizdat: 328 p.

10. Lishayev S.A. 2013. Igra ruin (materialy k esteticheskoy analitike ruin) [Game of the ruins (materials on the aesthetic analysis of the ruins)]. V kn.: Mixtura verborum' 2013: vremya, istoriya, pamyat': filosofskiy yezhegodnik [Mixtura verborum '2013: time, history, memory: philosophical yearbook]. Pod red. S.A. Lishaeva. Samara, Publ. Samara Humanitarian Academy: 84-100.

11. Lishayev S.A. 2015. Estetika ruin. [Aesthetics of the ruins]. V kn.: Yezhegodnik po fenomenologicheskoy filosofii [Phenomenological Philosophy Yearbook]. M., Publ. RGGU Publishing: 87-114. 
12. Mamardashvili M.K. 2014. Psikhologicheskaya topologiya puti T. 2 [Psychological topology of the path. Vol. 2.]. M., Publ. Merab Mamardashvili Foundation: 1232 p.

13. Metafizika Peterburga (Peterburgskiye chteniya po teorii, istorii i filosofii kul'tury). 1993. [Metaphysics of St. Petersburg (St. Petersburg readings on the theory, history and philosophy of culture)]. Spb., Publ. Eydos: 315 p. (in Russian).

14. Reshchikova I.P., Fokina T.P. 2007. Saratov v metafizicheskom naryade [Saratov in a metaphysical outfit]. Observatory of Culture, 3: 130-137.

15. Fedicheva K.V. 2010. Zabota o sebe: filosofskiy, ontologicheskiy i eticheskiy aspekty [Caring for oneself: philosophical, ontological and ethical aspects]. Bulletin of Pushkin Leningrad State University, 2(3) : 136-144.

16. Fokina T.P. 1998. Metafizika Saratova [Metaphysics of Saratov]. Publ. Volga, 1: 167 p.

17. Fuko M. 2006. Estetika sushchestvovaniya [Aesthetics of existence]. V kn.: Intellektualy i vlast': Izbrannyye politicheskiye stat'i, vystupleniya i interv'yu [Intellectuals and Power: Selected Political Articles, Speeches, and Interviews. Vol. 3]. M., 320 p.

18. Khaydegger M. 2003. Bytiye i vremya [Being and Time]. Khar'kov, Publ. Folio, 503 p.

\section{ИНФОРМАЦИЯ ОБ АВТОРЕ}

\section{Ромащенко Александр Александрович,} кандидат философских наук Института социального и производственного менеджмента Саратовского государственного технического университета имени Гагарина Ю.А., Саратов, Россия

\section{INFORMATION ABOUT THE AUTHOR}

Alexander A. Romanshchenko, $\mathrm{PhD}$ in Philosophy from the Institute of Social and Industrial Management of Saratov State Technical University named after Yu. A. Gagarin, Saratov, Russia 